\title{
O processo de trabalho no contexto da doação de órgãos e tecidos
}

\author{
The work process in the context of organ and tissue donation \\ El proceso de trabajo en el contexto de la donación de órganos y tejidos
}

\author{
Milleni Sousa Vieira'; LidyaTolstenko Nogueira ${ }^{I I}$
}

\begin{abstract}
RESUMO: Estudo descritivo, de abordagem qualitativa, que buscou avaliar aspectos relacionados ao processo de trabalho dos profissionais que atuam no Sistema de Captação, Notificação e Distribuição de Órgãos e Tecidos no Piauí. A amostra foi constituída de 29 sujeitos, entre enfermeiros, médicos, assistentes sociais e psicólogos. A obtenção de dados ocorreu por meio de entrevista, de outubro de 2011 a maio de 2012. A análise de conteúdo foi utilizada como referencial metodológico para o estudo dos depoimentos; em seguida, foram elaboradas categorias. Os resultados evidenciaram que equipe multiprofissional capacitada, família sensibilizada, conhecimento técnico e disponibilização de recursos físicos e materiais adequados são elementos necessários para a operacionalização do processo doação/transplante. A ausência desses elementos constitui barreiras a este processo. Assim, a identificação de fragilidades deve guiar o planejamento de estratégias que objetivem o aumento do número de doações e transplantes nos serviços de saúde.
\end{abstract}

Palavras-Chave: Transplantes; avaliação em saúde; serviços de saúde; enfermagem.

\begin{abstract}
This descriptive, qualitative study evaluated aspects of health personnel's work process in the Organ and Tissue Procurement, Notification and Distribution System in Piauí State. The sample of 29 subjects included nurses, doctors, social workers and psychologists. Data were collected by interview between October 2011 and May 2012. Content analysis gave the methodological framework for analysis of the interviewees' statements, after which categories were developed. The results showed that a skilled multidisciplinary team, a convinced family, technical expertise and availability of appropriate physical and material resources are needed to operationalize the donation/transplantation process. Their lack constitutes barriers to this process. Accordingly, identification of weaknesses should guide the planning of strategies to increase the number of donations and transplants in health services.

Keywords: Transplantation; health evaluation; health services; nursing

RESUMEN: Estudio descriptivo, con enfoque cualitativo, que buscó evaluar los aspectos relacionados con el proceso de trabajo de los profesionales que actúan en el Sistema de Captación, Notificación y Distribución de Órganos y Tejidos en Piauí. La muestra fue constituida por 29 sujetos, entre ellos: enfermeros, médicos, asistentes sociales y psicólogos. La obtención de datos se produjo a través de entrevista, de octubre de 2011 a mayo de 2012. El análisis de contenido se utilizó como marco metodológico para el estudio de los testimonios; a continuación, se han elaborado categorías. Los resultados mostraron que el equipo multidisciplinario capacitado, la familia sensibilizada, el conocimiento técnico y la puesta a disposición de recursos físicos y materiales adecuados son elementos necesarios para poner en práctica el proceso de donación/trasplante. Por otro lado, la falta de estos constituye barreras para el desempeño del proceso. De esa forma, la identificación de debilidades debe guiar la planificación de estrategias que tengan como objetivo aumentar el número de donaciones y trasplantes en los servicios de salud. Palabras Clave: Trasplantes; evaluación en salud; servicios de salud; enfermería.
\end{abstract}

\section{INTRODUÇÃO}

A evolução tecnológica relativa aos procedimentos envolvendo os transplantes de órgãos e tecidos apresentou um desenvolvimento notável, com reflexos importantes na sobrevida de milhares de pacientes.

Os transplantes consistem em terapêutica bem estabelecida, utilizados quando não existem outros tratamentos ou estes não alcançaram resultados. Desse modo, o transplante de órgãos e tecidos impõe-se como a última alternativa para pacientes que se encontram em fila de espera. A não realização dos transplantes implica consequências negativas em relação às probabilidades de cura, à sobrevida dos enxertos e pacientes, à natureza e à extensão das sequelas nos pacientes, nos familiares e na sociedade ${ }^{1}$. 
O desenvolvimento crescente do Brasil no setor de transplantes é fruto da atuação do Sistema Nacional de Transplantes (SNT), que normatiza a captação e distribuição de órgãos nos estados, por meio das Centrais Estaduais de Transplantes, bem como da sensibilização da população em geral sobre a importância do processo doação/transplante. A Política Nacional de Transplantes de órgãos e tecidos está regulamentada pelas leis federais $\mathrm{n}^{\circ} 9.434 / 97$ e $\mathrm{n}^{\circ} 10.211 / 01$, tendo como diretrizes a gratuidade da doação, o benefício em relação ao receptor e o não prejuízo em relação ao doador vivo ${ }^{2,3}$.

A realização dos transplantes de órgãos e tecidos é uma conquista para a sociedade em geral e para o sistema de saúde. Especificamente, no Brasil, esses procedimentos merecem destaque na medida em que mais de $90 \%$ dos transplantes são financiados por um sistema público de saúde.

Ademais, o processo de trabalho na doação de órgãos e tecidos deve ser compreendido para identificar os processos organizativos e os fatores que contribuem para a qualidade da assistência e o desenvolvimento das atividades envolvendo os transplantes.

Diante do exposto, este estudo teve como objetivo avaliar aspectos relacionados ao processo de trabalho dos profissionais que atuam no Sistema de Captação, Notificação e Distribuição de Órgãos e Tecidos no Estado do Piauí.

\section{Revisão DE Literatura}

A partir de 1990, ocorreram grandes avanços na área dos transplantes e consequente aumento no número de procedimentos. $\mathrm{O}$ desenvolvimento em áreas do conhecimento, como a imunologia, a hematologia, a hemoterapia, a enfermagem e o aperfeiçoamento das técnicas cirúrgicas permitiu que os transplantes fossem considerados terapêutica eficaz, proporcionando melhorias para pacientes com patologias crônicas e falência de órgãos ${ }^{4,5}$.

A atuação do SNT torna-se ampliada quando se considera que este é um dos maiores sistemas públicos de transplantes do mundo. No entanto, o sistema convive com problemas operacionais, existe um desperdício de órgãos e tecidos, baixos índices de notificações e uma desproporção entre doadores de órgãos e receptores aguardando em fila de espera ${ }^{6}$.

A carência de doadores de órgãos é um grande obstáculo para a efetivação dos transplantes no Brasil. Fatores como problemas estruturais de organização dos serviços de saúde, da dinâmica da atuação dos profissionais de saúde, além de problemas culturais concorrem para essa limitação ${ }^{4}$.

O processo de trabalho está relacionado ao modo como se realiza o trabalho ou o conjunto de procedimentos pelos quais os trabalhadores atuam, por intermédio dos meios de produção, sobre algum objeto para obterem determinado produto que possua uma finalidade. Os principais componentes do processo de trabalho são: os objetivos ou finalidades, os meios, o objeto e os agentes. Os objetivos ou finalidades definem a que se destina o processo de trabalho; os meios abrangem um amplo espectro e podem ser divididos em meios materiais e não materiais. Os primeiros contemplam os equipamentos, instrumentos, insumos e a estrutura física. Os últimos referem-se aos conhecimentos sistematizados ou não e às habilidades utilizadas no processo de trabalho. As condições de trabalho são consideradas meios. $\mathrm{O}$ objeto é algo sobre o qual se exerce a ação transformadora e os agentes são os sujeitos ou profissionais que executam as ações?

Fazendo uma analogia com o processo doação/ transplante, o objetivo é a redução da fila de espera obtida mediante o aumento de órgãos e tecidos disponíveis para transplantes e o aumento do número de transplantes. Os meios materiais são os insumos e equipamentos, tais como o transporte, o computador, linha telefônica, internet, exames disponíveis. Os meios não materiais são o conhecimento técnico sobre o processo. $\mathrm{O}$ objeto de trabalho é o potencial doador e as famílias. E os agentes são todos os profissionais envolvidos no processo.

\section{Metodologia}

Trata-se de um estudo descritivo, de abordagem qualitativa, desenvolvido em Teresina, Estado do Piauí, Nordeste do Brasil, nos espaços físicos da Central de Notificação, Captação e Distribuição de Órgãos e Tecidos (CNCDO), da Organização de Procura de Órgãos (OPO), da Comissão Intra-hospitalar de Doação de Órgãos e Tecidos (CIHDOTT) de um hospital público e do Banco de Tecidos Oculares (BTOC).

De um total de 32 profissionais, participaram do estudo 29, entre enfermeiros, médicos, assistentes sociais e psicólogos, com atuação nos serviços mencionados. Foram considerados critérios de inclusão no estudo: estar vinculado à instituição e atuar no processo doação/transplante há pelo menos um ano. Assim, três profissionais não atenderam aos referidos critérios.

Os dados foram obtidos mediante entrevista semiestruturada, constituída de duas partes: a primeira, com dados relativos a características dos profissionais; e a segunda, contendo questões abertas referentes ao objetivo do estudo. As entrevistas foram realizadas de outubro de 2011 a maio de 2012.

As entrevistas foram gravadas, transcritas na íntegra, e os depoimentos foram organizados e analisados segundo referencial metodológico da análise de conteúdo ${ }^{8}$. Em seguida, foram elaboradas as seguintes categorias: elementos necessários para a operaciona- 
lização do processo doação/transplante; fatores facilitadores e barreiras existentes à atuação no processo doação/transplante; a contribuição da instituição para o desempenho do processo doação/transplante, sob a ótica dos profissionais.

$\mathrm{Na}$ apresentação dos depoimentos, os profissionais entrevistados foram designados como $\mathrm{A}$, se proveniente da $\mathrm{CNCDO}$; $\mathrm{B}$, se proveniente da $\mathrm{OPO}$; $\mathrm{C}$, se proveniente da CIHDOTT e $\mathrm{D}$, se proveniente do BTOC. Na sequência, foi colocado um número arábico seguindo a ordem de realização da entrevista na respectiva instituição.

Em respeito aos princípios éticos, o projeto de pesquisa foi aprovado pelo Comitê de Ética em Pesquisa da Universidade Federal do Piauí (CAAE n ${ }^{\circ}$ 0159.0.045.000-11), e os participantes assinaram o Termo de Consentimento Livre e Esclarecido.

\section{Resultados e Discussão}

Foram entrevistados 20 enfermeiros, dois médicos, cinco assistentes sociais e dois psicólogos, com idade entre 28 e 55 anos, média de 43 anos. Em relação ao sexo, predominou o feminino, com 24(82,7\%) profissionais. Autores destacam que o aumento do número de mulheres no mercado de trabalho é algo irreversível e crescente nas duas últimas décadas ${ }^{9}$. A enfermagem é a profissão que constitui o maior contingente da força de trabalho em cuidados à saúde, amplamente distribuída e desempenhando os mais diversos papéis, funções e responsabilidades. Os enfermeiros prestam assistência aos indivíduos, famílias e comunidades nas mais diversas instituições, desde espaços comunitários até ambientes hospitalares de alta complexidade ${ }^{10}$.

Quanto ao tempo de atuação na instituição, os profissionais tinham entre 1 e 11 anos e tempo de experiência no processo doação/transplante entre 1 e 18 anos, com média de 6 anos, sendo que 19(65,5\%) profissionais relataram não possuir experiência anterior no setor de transplantes e 10(34,5\%) afirmaram possuir essa experiência.

\section{Elementos necessários para o processo}

As falas evidenciaram os meios de trabalho materiais e não materiais como imprescindíveis para a atuação no processo doação/transplante. Os profissionais da CNCDO destacaram a existência de uma equipe multiprofissional integrada e capacitada, com conhecimento técnico, disponibilização de recursos físicos e materiais, condições de trabalho adequadas e família sensibilizada.

[...] é importante que nós tenhamos uma equipe treinada e consciente em todas as etapas do processo doação/transplante [...] a família tem que ter uma conscientização prévia porque a família é extremamente importante, só ela vai decidir isso [...] precisamos ter profissionais extremamente qualificados [...] (A13)

[...] é indispensável que a gente tenha o sistema de informação do Ministério da Saúde [...] o computador [...] também o próprio telefone [...] carro com motorista também é fundamental! E a gente tem. (A3)

Para os profissionais da OPO e da CIHDOTT, além do trabalho em equipe, do conhecimento técnico e dos recursos físicos e materiais, a ética e a humanização foram citadas como necessárias para o processo doação/transplante.

[...] eu diria que o conhecimento técnico sobre o processo doação/transplante, a ética profissional e, a partir daí, a questão também da humanização. Além dos insumos que se fazem necessários para o desenvolvimento desse trabalho. (B2)

[...] eu preciso de uma equipe capacitada, preciso ter profissionais de diversos setores, mas principalmente dos setores onde tem ventilação mecânica invasiva como a UTI, as emergências, e esses profissionais comprometidos com a manutenção do potencial doador [...] (C6)

Frequentemente, o setor saúde tem que responder às demandas por intervenções tecnológicas de alta complexidade e especialidade, que ocorrem nos hospitais de atendimento terciário, bem como a outras demandas ${ }^{10}$. O processo doação/transplante é complexo e pressupõe a disponibilidade e o investimento em recursos materiais e humanos.

Além disso, a relevância dos aspectos éticos deve ser considerada no contexto dos transplantes. Apesar do avanço técnico-científico e dos benefícios conquistados com os transplantes para a saúde da população, esses procedimentos ainda convivem com questionamentos éticos ${ }^{11}$.

Nesse sentido, os profissionais que atuam nesse processo devem estar respaldados nos princípios da ética, da legalidade e da humanização. E, ainda, devem considerar a família como um elemento fundamental no processo doação/transplante, uma vez que apenas ela, devidamente acolhida e informada, é quem vai consentir ou não a doação. As experiências dos familiares devem ser consideradas no desenvolvimento de protocolos assistenciais ${ }^{12,13}$.

Os profissionais do BTOC relataram como elementos necessários a existência da equipe capacitada e de insumos necessários para viabilizar a conservação dos tecidos oculares.

É importante termos uma equipe de profissionais [...] e também a questão do nosso meio de preservação, nós trabalhamos como Optisol-GS ${ }^{\circledR}$, que é um dos meios de preservação para tecidos oculares. (D1)

Destaca-se a importância do trabalho em equipe referida pelos profissionais dos serviços pesquisados. 
O trabalho em equipe aqui neste serviço é essencial [...] quando se identifica o potencial doador existe a necessidade de ter alguém avisando [...] Há a necessidade da equipe que faz a abordagem chegar em tempo hábil para que a doação se concretize [...] uma equipe transplantadora deve ser acionada e até o laboratório que realiza os exames [..]. Então, é uma rede e a gente só trabalha se a rede existir. (A6)

$\mathrm{O}$ interesse pelo trabalho em equipe multidisciplinar tem se fortalecido, visto que valoriza os diversos saberes e práticas na perspectiva de uma abordagem integral. A articulação de equipes multidisciplinares sistematiza o trabalho e proporciona melhorias nos resultados ${ }^{14}$. Considerando a natureza do seu objeto, no processo doação/transplante o trabalho multidisciplinar é de fundamental importância.

\section{Fatores facilitadores e barreiras}

Como fatores facilitadores referidos pelos profissionais para a atuação no processo doação/transplante foram destacados o conhecimento sobre o processo, a realização de treinamentos, a relação com a equipe interdisciplinar e a colaboração das equipes assistenciais, bem como o apoio da gestão. As falas a seguir explicitam esses resultados:

[...] o fato de conhecer e gerir o sistema facilita [...] Outra coisa que facilita é o fato de a gente ter feito por um bom tempo o serviço de ponta, assistencial, de busca mesmo, de contato com o paciente (doador). (A8)

[...] são os conhecimentos adquiridos através dos referenciais teóricos que a gente tem acesso, das capacitações que a gente participa, e do nosso dia-a-dia [...] (A5)

[...] a compreensão e a colaboração dos profissionais facilitam muito o nosso trabalho, desde a notificação até um acolhimento inicial da família [...] outro fator é a gestão, uma gestão que se mostre também entendedora desses processos da CIHDOTT, processos pertinentes ao SNT [...] (C2)

Os treinamentos e capacitações proporcionam o desenvolvimento de competências específicas e habilidades, direcionam a prática dos profissionais e promovem o desenvolvimento técnico ${ }^{15}$. Por sua vez, a existência de uma equipe multiprofissional integrada permite a interação entre os agentes envolvidos com o reconhecimento dos diferentes saberes e da autonomia técnica de cada um ${ }^{16}$. Para viabilizar o processo doação/ transplante, é necessária a existência de equipes multiprofissionais treinadas e capacitadas ${ }^{11}$.

A importância da colaboração das equipes assistenciais se deve ao fato de estas serem responsáveis pela notificação de um possível doador às comissões ou à Central, bem como pela condução e manuseio adequado do potencial doador. A manutenção do potencial doador inclui desde o reconhecimento e a confirmação da morte encefálica (ME), observadas as formalidades legais, até a prevenção, detecção precoce e o manuseio das principais complicações advindas da $\mathrm{ME}$, para garantir que os órgãos e tecidos sejam captados nas melhores condições funcionais ${ }^{17}$.

Ademais, o apoio da gestão torna-se relevante na medida em que o processo de trabalho em uma política pública é permeado por conflitos e necessidades que devem ser equacionados para atender aos objetivos e à finalidade da política em questão ${ }^{18}$.

A existência de uma legislação que normatiza o processo envolvendo os transplantes também foi referida como um fator facilitador.

A gente tem um conjunto de leis e portarias, uma legislação extensa. Existe um consolidado dessa legislação, e isto nos facilita para ter o domínio do que pode e o que não pode [...] (A6)

A Política de Transplantes no Brasil está fundamentada nas leis federais $n^{\circ} 9.434 / 97$ e $n^{0} 10.211 / 01$ e contém as diretrizes que norteiam todo o processo de transplantes no país. Existe extensa legislação que trata sobre as doações e os transplantes ${ }^{2,3}$.

Deve-se ressaltar a importância da Portaria $n^{\circ}$ 2.600/09, por constituir o Regulamento Técnico do SNT, estabelecendo normas específicas para o seu funcionamento, das CNCDOs e demais instâncias do sistema ${ }^{19}$. A legislação normatiza as atividades que envolvem os transplantes, aprimorando o funcionamento e o gerenciamento dessa política.

Em relação às barreiras existentes para a atuação no processo doação/transplante, os entrevistados relataram, principalmente, as dificuldades estruturais, como a falta do exame complementar para o diagnóstico de ME disponível nas 24 horas no serviço público e o desconhecimento e falta de apoio dos profissionais da assistência sobre o processo de doação de órgãos e tecidos, conforme demonstram as seguintes falas:

[...] precisamos que os hospitais tenham equipamentos de alta complexidade pra manter esses potenciais doadores, precisamos de boa terapia intensiva e equipamentos, como Dopplertranscraniano, Eletroencefalografia, a arteriografia cerebral e infelizmente, os nossos dois hospitais públicos do Estado, nenhum faz estes exames. (A13)

[...] coloco em primeiro lugar a identificação tardia dos potenciais doadores, o retardo na abertura do protocolo e o nosso maior calo que é o exame complementar de imagem [...] existe um certo receio da parte dos profissionais em realizar o exame [...] (A12)

[...] o desconhecimento do que é morte encefálica, do que é processo de doação de órgãos [...] a desinformação é muito grande entre profissionais, imprensa, comunidade, estudantes, professores [...] a falta de apoio também das instituições que a gente trabalha, dos próprios colegas de UTI [...] (B3) 
Estudo realizado em Minas Gerais evidenciou como principais obstáculos para a efetivação do processo doação/transplante a falta de estrutura dos hospitais para comprovar o diagnóstico de ME e para manter um potencial doador, o conhecimento inadequado dos médicos responsáveis quanto ao protocolo de $\mathrm{ME}$ e à legislação dos transplantes e o atraso da notificação de $\mathrm{ME}^{20}$.

No Piauí, o exame complementar utilizado para o diagnóstico de ME é a arteriografia, cuja realização ocorre em clínica particular conveniada com o Sistema Único de Saúde. Na prática, isso implica o deslocamento do potencial doador do hospital onde se encontra internado para essa clínica, mobilizando vários profissionais e recursos simultaneamente ${ }^{21}$.

Ainda existe um despreparo dos profissionais de saúde no diagnóstico de $\mathrm{ME}$, na identificação do potencial doador, na notificação às Centrais de Transplantes, bem como na entrevista familiar para a solicitação da doação, com reflexos importantes no número de óbitos na lista de espera ${ }^{11}$.

\section{A contribuição da instituição no processo}

A CNCDO, segundo os profissionais entrevistados, contribui para o setor de transplantes, sendo o órgão regulador e coordenador do processo doação/ transplante em âmbito estadual. Ademais, o controle da lista de espera e da distribuição de órgãos e tecidos são atribuições exclusivas da Central de Transplantes, conforme ilustram os depoimentos a seguir:

[...] sem a Central não seria possível o transplante acontecer, já que a gente regula a lista, sabemos para quem aquele órgão está sendo destinado, regulamos quem transplanta, quem são estas equipes, quem está autorizado a fazer ou não o transplante [...] a Central tem um papel de suma importância [...] (A6)

[...] é o centro regulador de todas as etapas do processo doação/transplante e foi a partir da Central que se criaram as CIHDOTTs, se criaram as OPOs, que as atribuições começaram a ser redistribuidas entre os novos órgãos [...] (A12)

As Centrais são responsáveis pela coordenação das atividades de transplantes em âmbito estadual, realizando as inscrições e acompanhamento dos receptores, as notificações de potenciais doadores no sistema e viabilizando a logística de todo o processo de doação, desde o diagnóstico de $\mathrm{ME}$ até a retirada e a alocação dos órgãos e tecidos ${ }^{22}$.

A CNCDO deve atuar junto aos estabelecimentos de saúde por meio das OPOs e das CIHDOTTs, proporcionando a construção de uma rede de apoio e regulação dos serviços de terapia intensiva, emergências e administrativos ${ }^{19}$.

Para os profissionais da OPO, a contribuição para o setor de transplantes ocorre em função do aumento das buscas ativas, das doações e captações com a expansão do serviço para os hospitais da rede de saúde da capital.

A gente trabalha fazendo a busca ativa, então, essa busca tem aumentado o número de captações de órgãos aqui no Estado com a OPO. Isso já foi reconhecido pela própria Central de Transplantes [...] (B5)

A criação das OPOS e das CIHDOTTs constitui um avanço significativo no processo de captação de órgãos. A OPO proporcionou a extensão do território geográfico e populacional para a atuação do processo doação/transplante. Já a CIHDOTT, com atuação intra- hospitalar, permitiu o direcionamento para a detecção precoce de potenciais doadores e para o planejamento das entrevistas com os familiares, de forma a atender a esses usuários ${ }^{22,23}$.

É importante ressaltar que a OPO deve ter seus limites de atuação definidos por critérios populacionais e geográficos, proporcionando a detecção e viabilização do potencial doador de órgãos e tecidos para transplantes ${ }^{24}$.

A CIHDOTT, de acordo com os profissionais entrevistados, tem sua contribuição pautada na localização próxima às equipes assistenciais, na busca ativa, no acolhimento das famílias dos doadores e na promoção de um processo educativo dos profissionais.

[... a Comissão deu uma impulsionada no número de transplantes do Estado por estar no local onde acontece, por estar acompanhando mais de perto [...] (C1)

A gente está nessa linha de frente para aumentar a oferta de órgãos e com qualidade [...] sem que cause maiores danos à família doadora, e também esse processo educativo dos profissionais [...] (C2)

A CIHDOTT possui uma localização estratégica intra-hospitalar, favorecendo as buscas ativas, o acolhimento das famílias e a promoção da educação continuada. Tanto a OPO como a CIHDOTT devem prover a educação permanente dos profissionais das instituições onde atuam sobre os aspectos do processo ${ }^{19}$.

Segundo os profissionais do BTOC, uma das principais contribuições para o processo doação/transplante são as orientações e as atividades educativas realizadas pela instituição.

[...] a gente procura trabalhar na associação de bairro, nas escolas de nível médio, nas universidades, orientando os profissionais [...] o Banco de Olhos contribui com a doação e os transplantes nessa parte de divulgação, de palestra, de orientação. (D1)

Uma das competências dos Bancos de Tecidos Oculares Humanos consiste em participar, sob a coordenação da CNCDO do respectivo estado, de ações de promoção, divulgação e esclarecimento à população a respeito da importância da doação de órgãos e tecidos, com o objetivo de aumentar o número de doações e captações ${ }^{25}$. 


\section{ConClusão}

Para os sujeitos entrevistados, além das lacunas estruturais, a falta de apoio dos profissionais da assistência constitui barreira para atuação no processo doação/ transplante. É fundamental a efetiva implementação de atividades de educação permanente direcionada à equipe de saúde sobre o processo de doação de órgãos e tecidos e a importância dos transplantes, objetivando a compreensão e a colaboração de todos na rede hospitalar, especialmente as emergências e unidades de terapia intensiva.

Os profissionais entrevistados demonstraram conhecimento e compromisso com o processo doação/ transplante e referiram a importância do trabalho em equipe para esse processo. Equipes multiprofissionais capacitadas e disponíveis para colaborar com a doação e os transplantes constituem um dos alicerces para o sucesso de cada etapa do processo.

A atuação do profissional enfermeiro está presente em todas as etapas do processo doação/transplante, desde a identificação do potencial doador até o acompanhamento pós-transplante. Essa presença demonstra a importância das ações e da assistência de Enfermagem aos usuários do setor de transplantes.

O conhecimento do processo de trabalho dos profissionais nesse sistema evidenciou a importância das atividades desenvolvidas no contexto da doação de órgãos e tecidos e dos transplantes. A identificação de fragilidades deve guiar o planejamento de estratégias que objetivem o aumento do número de doações e transplantes nos serviços de saúde.

Como limitação do estudo, não foi contemplada a análise das equipes assistenciais hospitalares e das equipes transplantadoras e instituições credenciadas para a realização de transplantes. Novos estudos são sugeridos para a abordagem de tais elementos.

\section{REFERÊNCIAS}

1.Marinho A, Cardoso SS, Almeida, VV. Disparidades nas filas para transplantes de órgãos nos estados brasileiros. Cad Saúde Pública [Scielo-Scientific Electronic Library Online]. 2010 [citado em11 fev 2015]; 26(4):786-96. Disponível em: http://www.scielo.br/pdf/ csp/v26n4/20.pdf

2.Brasil. Lei Federal no 9.434, de 4 de fevereiro de 1997: altera dispositivos da Lei n. 9.434/97, que dispõe sobre a remoção de órgãos, tecidos e partes do corpo humano para fins de transplante e tratamento, e dá outras providências [Internet]. 1997 [citado em 11 mai 2015]. Disponível em: http://bvsms.saude.gov.br/php/level.ph p?lang $=$ pt\& component $=44 \&$ \&item $=21$

3.Governo Federal (Br). Lei no 10.211, de 23 março de 2001: dispõe sobre a remoção de órgãos, tecidos e partes do corpo humano para fins de transplante e tratamento, e dá outras providências [Internet]. 2001 [citado em 11 mai 2012]. Disponível em: http://portal.saude.gov.br/ portal/saude/visualizar_texto.cfm?idtxt $=31821$

4.Boing JS. Avaliação do desempenho do sistema de captação de órgãos e tecidos para transplantes [dissertação de mestrado]. Florianópolis(SC): Universidade Vale do Itajaí; 2008.

5.Roza, BA. Captação de órgãos para transplantes. In: Knobel, E. Condutas no paciente grave. São Paulo: Atheneu; 2006. p.1753-61.

6.Marinho A. Um estudo sobre as filas para transplantes no Sistema Único de Saúde. Cad Saúde Pública. 2006;22:2229-39.

7.Faria HP, Werneck MAF, Santos MA, Teixeira PF. Processo de trabalho em saúde. Belo Horizonte (MG): Nescon/UFMG, Coopmed; 2009. p. 20-7.

8.Bardin L. Análise de conteúdo. Tradução de Luis Antero Reto e Augusto Pinheiro. São Paulo: Edições 70; 2011. 9. Oliveira ERA, Garcia AL, Gomes MJ, Bittar TO, Pereira AC. Gênero e qualidade de vida percebida: estudo com professores da área da saúde. Ciênc saúde coletiva [Scielo-Scientific Electronic Library Online]. 2012 [citado em 10 ago 2015]; 17:741-7. Disponível em: http:// www.scielo.br/pdf/csc/v17n3/v17n3a21.pdf

10.Rocha SMM, Almeida MCP. O proceso de trabalho da enfermagem em saúde coletiva e a interdisciplinaridade. Rev Latino-Am Enferm. 2000; 8(6):96-101.

11.Barros PMR, Araújo EC, Lima LS. Transplantes de órgãos e tecidos: aspectos históricos, ético-legais, emocionais e repercussão na qualidade de vida. Rev enferm UFPE [Internet]. 2009 [citado em 20 mar 2015]; 3:1192-201. Disponível em: http://www.ufpe.br/revistaenfermagem/index.php/revista/article/view/137/pdf_992 12.Moraes EL, Massarollo MCKB. Recusa de doação de órgãos e tecidos para transplante relatados por familiares de potenciais doadores. Acta Paul Enferm. 2009; 22:131-5.

13.Erbs JL, Schirmer J, Possa S, Roza BA. Analise dos obitos de um hospital: busca ativa por potenciais doadores de córneas. Rev enferm UERJ. [Internet] 2012 [citado em 10 abr 2015]; 20:334-7. Disponível em: http://www. facenf.uerj.br/v20n3/v20n3a09.pdf

14.Tonetto AM, Gomes WB. A prática do psicólogo hospitalar em equipe multidisciplinar. Estudos da Psicologia [Scielo-Scientific Electronic Library Online]. 2007 [citado em 10 ago 2015]; 24(1):89-98. Disponível em: http://www.scielo.br/pdf/estpsi/v24n1/v24n1a10.pdf 15.Pardal L. Capacitação profissional: educação e cuidado em saúde. Rev Saúde \& Gestão. 2007; 3:13-5.

16.Ribeiro EM, Pires D, Blank VLG. A teorização sobre proceso de trabalho em saúde como instrumental para análise do trabalho no Programa Saúde da Família. Cad Saúde Pública. [Scielo-Scientific Electronic Library Online]. 2004 [citado em10 ago 2015]; 20:438-46. Disponível em: http://www.scielosp.org/pdf/csp/v20n2/11.pdf 17.Guetti NR, Marques IR. Assistência de enfermagem ao potencial doador de órgãos em morte encefálica. Rev Bras Enferm. 2008; 61:91-7.

18.Backes DS, Backes MS, Erdmann AL, Büscher A. O papel profissional do enfermeiro no Sistema Único de 
Saúde: da saúde comunitária à estratégia de saúde da família. Ciênc saúde coletiva. 2012; 17:223-30.

19.Ministério da Saúde (Br). Portaria no 2.600/09. Aprova o Regulamento Técnico do Sistema Nacional de Transplantes. Brasília (DF): Gabinete Ministerial; 2009. 20.Machado EL, Cherchiglia ML, Acúrcio FA. Perfil e desfecho clínico de pacientes em fila de espera por transplante renal, Belo Horizonte (MG, Brasil), 2000. 2005. Ciênc saúde coletiva. [Scielo-Scientific Electronic Library Online]. 2011 [citado em 20 mar 2015]; 16(3):1981-92. Disponível em: http://www.scielosp.org/ pdf/csc/v16n3/32.pdf

21. Vieira MS, Sales RLUB, Nogueira LT. Evolução dos transplantes de órgãos e tecidos: alternativas para a sobrevida de pacientes em fila de espera. Rev Enferm UFPE [Internet]. 2012 [citado em 05 ago 2015]; 6:1918-26. Disponível em: http:/www.ufpe.br/revistaenfermagem/ index.php/revista/article/view/2995
22.Medina-Pestana JO, Galante NZ, Tedesco-Silva Jr H, Harada KM, Garcia VD, Abbud-Filho M. O contexto do transplante renal no Brasil e sua disparidade regional geográfica. J Bras Nefrol. 2011; 33:472-84.

23. Houri LF, Oliveira CD, Souza CV, Moura MR, Araujo LMF, Oliveira VD, et al. Intentionality of organ/ tissues donation for transplantation within a brazilian hospital complex. Transplant Proc. [Medline]. 2012 [citado em 10 mar 2015]; 44:2272-5. Disponível em: http://www.transplantation-proceedings.org/article/ S0041-1345(12)00717-8

24.Ministério da Saúde (Br). Portaria no 2.601/09. Institui, no âmbito do Sistema Nacional de Transplantes, as Organizações de Procura de Órgãos. Brasília (DF): Gabinete Ministerial; 2009.

25.Ministério da Saúde (Br). Portaria no 239/04. Regulamenta o funcionamento dos Bancos de Tecidos Oculares Humanos. Brasília (DF):Gabinete Ministerial; 2004. 